\title{
In silico study: Assessment of the inhibition of cyclo-oxygenase 2 by ibuprofen by validating molecular docking and cardiovascular effects reported during the COVID 19 pandemic
}

\author{
Hamza Nadjib Merad-Boudia, Majda Dali-Sahi, Baya Guermouche, Nouria Dennoun-Medjati \\ Department of Biology, Analytical Chemistry and Electrochemistry laboratory, \\ Abou bekr Belkaid University, Tlemcen, 13000, Algeria \\ Email: mbhnaguib@yahoo.fr
}

\begin{abstract}
Introduction The Covid 19 pandemic has put the cardiovascular risk incurred when using nonsteroidal anti-inflammatory drugs at the heart of the discussion. Based on the information currently available, WHO does not recommend the use of ibuprofen. the objective is to evaluate the inhibition of cyclooxygenase 2 by ibuprofen by validating molecular docking.

Method The crystallographic structure of ibuprofen bound to cyclooxygenase-2 was obtained from the Protein Data Bank (PDB) at a resolution $<3.00 \AA$.

The receiver was visualized using Discovery Studio Visualizer version 2.5.5. It was efficiently prepared using AutoDock / Vina software.

The 3D structure of Ligand (Ibuprofen) was downloaded from the Drugbak database (https://www.drugbank.ca/): Accession number DB01050

Results Molecular docking was chosen as the first-line discrimination of the ibuprofen-COX2 intercation for the in silico study of putative competitors. The complex formed by Ibuprofen-COX 2 from the experimental model gives a docking score (Affinity: $-7.3(\mathrm{kcal} / \mathrm{mol}$ ) with a mean square deviation of (RMSD = 23.884).

Conclusion The evaluation of the inhibition of cyclo-oxygenase 2 by ibuprofen was validated by molecular docking. Cardiovascular effects already reported in patients treated with traditional non-steroidal antiinflammatory drugs and coxibs have been observed in patients with COVID 19. Molecular docking becomes an essential step in drug discovery to explore other drug targets
\end{abstract}

Keywords: Cyclooxygenase-2, Ibuprofen, Molecular docking, Covid 19

\section{Introduction}

The use of ibuprofen during COVID 19 infection has been prohibited. severe forms reported in young patients who had no health problems after using nonsteroidal anti-inflammatory drugs (Day 2020)

Several previous studies have shown a complicated course with an increased incidence of empyema, lung cavitation, and prolonged intensive care unit stay when nonsteroidal anti-inflammatory drugs (NSAIDs) were used in patients with pneumonia (Voiriot and al. 2019).

Cardiovascular side effects associated with NSAIDs have been previously reported including hypertension, heart failure and kidney failure (Karsh 2006).

Coxibs were developed as an alternative solution to the gastrointestinal toxicity of NSAIDs. Unfortunately, an increased risk of cardiovascular episodes has been observed with all coxibs and, where data were available, with traditional NSAIDs such as diclofenac and ibuprofen (Gislason and al. 2006). These risks have led to a reevaluation of these traditional therapies.

This is why we can no longer underestimate the risks of cyclo-oxygenase inhibitors, whether traditional NSAIDs or coxibs. Moreover, the risks are not limited to long-term use; clinically serious adverse cardiovascular episodes have been reported during the first days of treatment (Karsh 2006)

In view of the scientific debates led by researchers around the world on the report, the objective is to evaluate the inhibition of cyclo-oxygenase 2 by ibuprofen through a molecular docking validation. 


\section{Materials and methods}

To locate the sites of interaction, four different categories of COX inhibitors have been documented by Smith et al.,(Smith and al. 2011). Several works have determined the crystal structures of COX-1 and COX-2 in complex with inhibitors and substrates (Kurumbail and al. 1996), (Vecchio and al. 2011). Selinsky et al determined the crystal structure of IBP bound to COX-1. (Selinsky and al. 2001) .

However, the analgesic and anti-inflammatory effects of ibuprofen (IBP) arise from inhibition of COX-2 rather than COX-1(Laneuville and al. 1994). In order to compare the mode of binding of IBP to COX-2 versus COX1 , and to reveal a possible mechanism of selective substrate inhibition mediated by IBP, Orlando et al determined the crystal structure murine (mu) COX-2 complexed with Ibuprofen (IBP) (Orlando and al. 2015). The coordinates of the X-ray crystals of COX-2 in complex with ibuprofen (IBP formula: C13 H18 O2) (PDB ID: 4PH9) in Table 1, 2, 3, were extracted from the RCSB database ( http: / /www.rcsb.org/pdb). This is selected for modeling studies.

Table 1: Macromolecules in Ibuprofen (IBP) Bound to Cyclooxygenase-2 Complex

\begin{tabular}{|c|c|c|c|c|}
\hline \multicolumn{5}{|l|}{ Entity ID : 1} \\
\hline Molecule & Chains & $\begin{array}{l}\text { Sequence } \\
\text { Length }\end{array}$ & Organism & Details \\
\hline Prostaglandin G / H synthase 2 & A, B & 551 & $\underline{\text { Mus musculus }}$ & $\begin{array}{l}\text { Mutation (s): } 0 \\
\text { Gene Noms: } \underline{\text { Ptgs } 2}, \underline{\text { Cox }-2}, \\
\text { Cox } 2, \underline{\text { Pghs-b }}, \underline{\text { Tis } 10} \\
\text { EC: } \underline{1.14 .99 .1}\end{array}$ \\
\hline
\end{tabular}

Table 2: Oligosaccharides in Ibuprofen in (IBP) bound to cyclooxygenase-2 complex

\begin{tabular}{|c|c|c|c|}
\hline \multicolumn{4}{|l|}{ Entity ID : 2} \\
\hline Molecule & Chains & $\begin{array}{l}\text { Sequence } \\
\text { Length }\end{array}$ & Glycosylation \\
\hline $\begin{array}{l}\text { 2-acétamido-2-désoxy-bêta-D-glucopyranose- (1-4) } \\
\text {-2-acétamido-2 désoxy-bêta-D-glucopyranose }\end{array}$ & $\mathrm{C}, \mathrm{D}$ & 2 & N-glycosylation \\
\hline \multicolumn{4}{|l|}{ Entity ID : 3} \\
\hline Molecule & Chains & $\begin{array}{l}\text { Sequence } \\
\text { Length }\end{array}$ & glycosylation \\
\hline $\begin{array}{l}\text { alpha-D-mannopyranose- (1-4) -2-acétamido-2- } \\
\text { désoxy-bêta-D-glucopyranose- }(1-4) \text {-2-acétamido- } \\
\text { 2-désoxy-bêta-D-glucopyranose }\end{array}$ & $\mathrm{E}$ & 3 & N-glycosylation \\
\hline
\end{tabular}


Table 3: Small molecules of ibuprofen (IBP) bound to the cyclooxygenase-2 complex

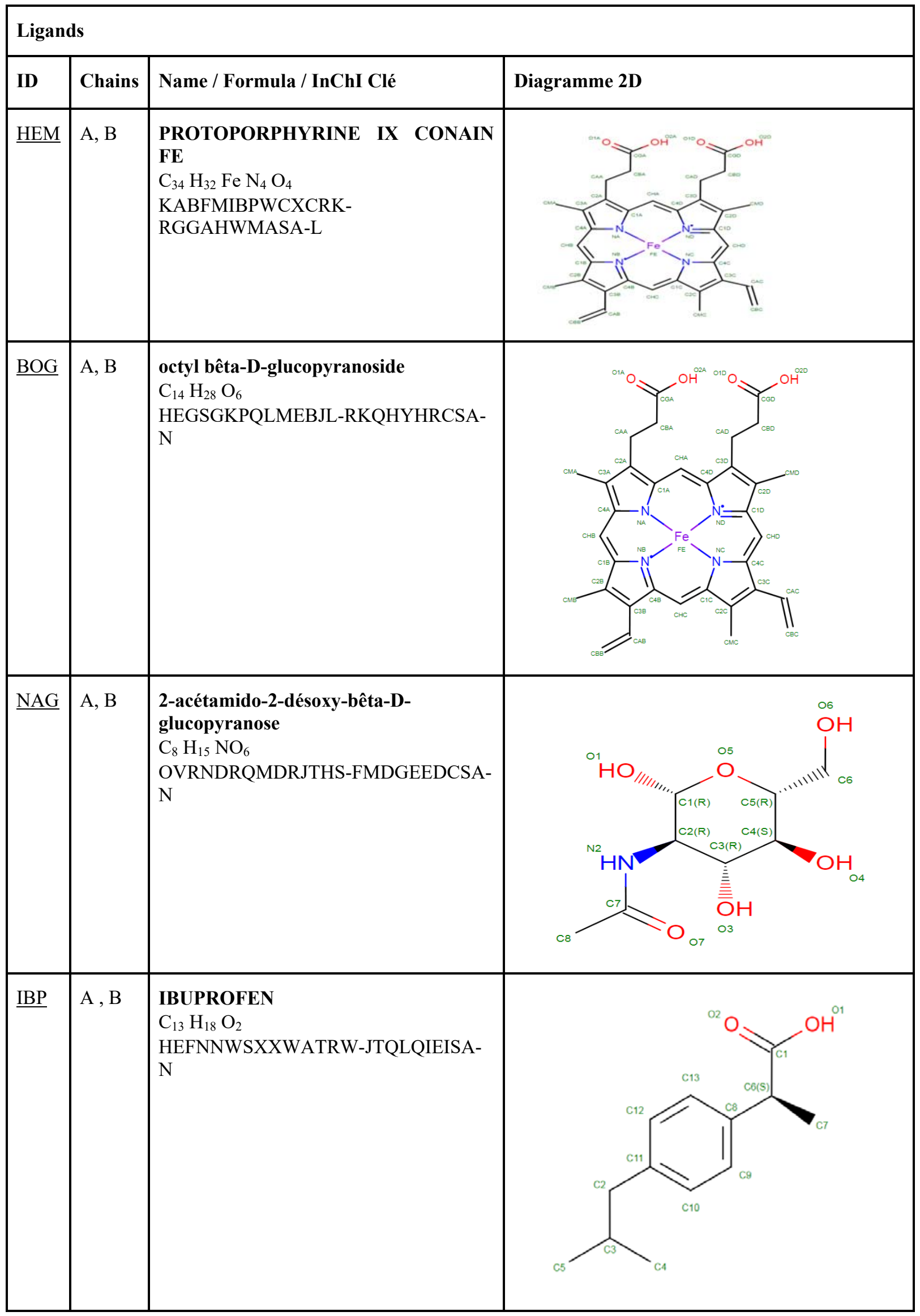




\begin{tabular}{|c|c|c|c|}
\hline$\underline{\mathrm{AKR}}$ & $\mathrm{A}, \mathrm{B}$ & $\begin{array}{l}\text { ACRYLIQUE ACID } \\
\mathrm{C}_{3} \mathrm{H}_{4} \mathrm{O}_{2} \\
\text { NIXOWILDQLNWCW-UHFFFAOYSA- } \\
\mathrm{N}\end{array}$ & 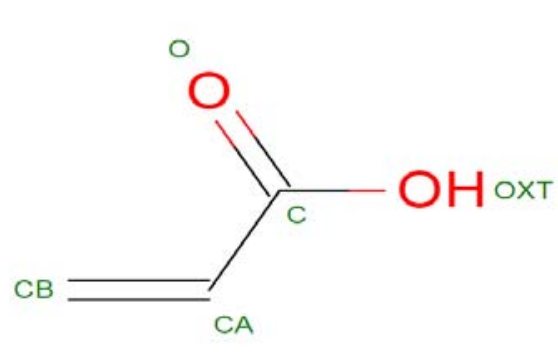 \\
\hline$\underline{\text { EDO }}$ & A, B & $\begin{array}{l}\text { 1,2-ÉTHANEDIOL } \\
\mathrm{C}_{2} \mathrm{H}_{6} \mathrm{O}_{2} \\
\text { LYCAIKOWRPUZTN-UHFFFAOYSA- } \\
\mathrm{N}\end{array}$ & $\mathrm{HO}_{01}^{\mathrm{C} 1}$ \\
\hline
\end{tabular}

\section{1- Protein preparation}

The X-ray crystallographic structure of ibuprofen bound to cyclooxygenase-2 (4PH9) (from Mus musculus) was obtained from the Protein Data Bank (PDB) (http://www.rcsb.org) at resolution <3.00 $\AA$ (resolution: $1.81 \AA$, free R-value: 0.197, working R-value: 0.160, observed R-value: 0.162).

This file is not directly used by Autodock 1.5.6 tools, it was first viewed using Discovery Studio Visualizer version 2.5.5. Discovery Studio is a biological molecular design solutions software package for chemists and computational biologists. (Discovery Studio 2.5 (CDOCKER Dock, Dassault Systemes BIOVIA, USA) Discovery Studio facilitates the examination of the properties of large and small molecules

Water molecules, ligands and other heteroatoms have been removed from protein molecules. These crystallographic structures were preserved without any treatment for molecular anchoring. The protein PDB files were efficiently prepared using AutoDock / Vina (Molecular Graphics Lab, The Scripps Research Institute Plugin, La Jolla, CA, USA) and saved as pdbqt files. Polar hydrogens and Kollman chrages have been added.

\section{2- 2- Preparation of the ligand}

The 3D structure of Ligand (Ibuprofen) was downloaded from the Drugbak database (https://www.drugbank.ca/): Accession number DB01050. Torsional connections have been verified. Ligand was saved in the same anchor folder in pdbqt format. The charges were then added.

\section{3- Molecular docking protocol}

Docking calculations were performed using standard AutoDock Vina defaults. The active site was placed in a 40 $\times 50 \times 40 \AA$ cubic box at the geometric center of the selected flexible residue set, which has $0.375 \AA$ as the grid point spacing

The values of the root mean square deviation (RMSD) between the mooring and the initial poses were calculated. The resulting best poses were ranked based on Vina scores (kcal / mol). assessed by free binding energies (S score, $\mathrm{kcal} / \mathrm{mol}$ ) and binding interactions between the ligand atom and the active site residues. 


\section{Result}

Molecular docking was chosen as the first-line discrimination of the ibuprofen-COX2 intercation as a structural discrimination procedure based on the in silico prediction of putative competitors (Liu and al. 2017). The structural differences of each molecule also influence its interaction with COX2 (figure 1)<smiles>CCN(CCO)CCCC(C)Nc1ccnc2cc(Cl)ccc12</smiles>

Hydroxychloroquine

$\left(\mathrm{C}_{18} \mathrm{H}_{26} \mathrm{ClN}_{3} \mathrm{O}\right)$<smiles>CS(=O)(=O)c1ccc(C2=C(c3ccccc3)C(=O)OC2)cc1</smiles>

Rofecoxib

$\left(\mathrm{C}_{17} \mathrm{H}_{14} \mathrm{O}_{4} \mathrm{~S}\right)$<smiles>CC(C)Cc1ccc(C(C)C(=O)O)cc1</smiles>

Ibuprofen

$\left(\mathrm{C}_{13} \mathrm{H}_{18} \mathrm{O}_{2}\right)$<smiles>Cc1ccc(-c2cc(C(F)(F)F)nn2-c2ccc(S(N)(=O)=O)cc2)cc1</smiles>

Celecoxib

$\left(\mathrm{C}_{17} \mathrm{H}_{14} \mathrm{~F}_{3} \mathrm{~N}_{3} \mathrm{O}_{2} \mathrm{~S}\right)$<smiles>COc1ccc2cc([C@@H](C)C(=O)O)ccc2c1</smiles>

Naproxen

$\left(\mathrm{C}_{14} \mathrm{H}_{14} \mathrm{O}_{3}\right)$.<smiles>O=C(O)Cc1ccccc1Nc1c(Cl)cccc1Cl</smiles>

Diclofenac

$\left(\mathrm{C}_{14} \mathrm{H}_{11} \mathrm{Cl}_{2} \mathrm{NO}_{2}\right)$

Figure 1: Structure of Ibuprofen and other drugs with anti-inflammatory action (By DrugBank)

Each COX isoform is a structural homodimer which functions as a heterodimer. According to Mitchener et al, one subunit, containing the required heme prosthetic group, acts as a catalytic site, while the other serves as an allosteric site (Mitchener and al. 2015). Previous evidence suggests that inhibitors may act at one or both sites, depending on the structure and concentration of the inhibitor(Dong and al. 2013) . Regardless of the site, Picot et al., Identified an open area called a "lobby" through which binding requires that a small molecule must first enter (Picot and al. 1994)

As shown in Figure 2, ibuprofen was identified in the pocket of the COX2 enzyme binding site.

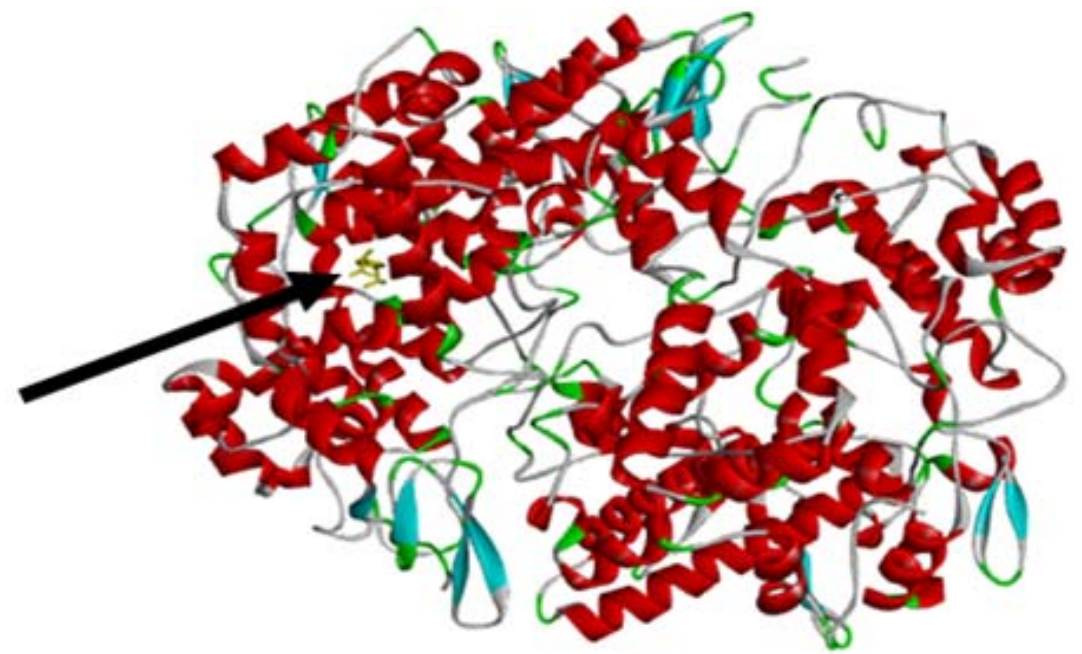

Figure 2: Ibuprofen in the pocket of the COX2 enzyme binding site (with Discovery Studio 2.5 software). 
The active site was placed in a cubic box at the geometric center of the selected flexible residue set at $0.375 \AA$ as the grid point spacing

The coordinates of the Grid Box (number of points X, Y, Z dimensions and spacing) for the Ibuprofen-COX2 model (shown in Figure 3) were noted.

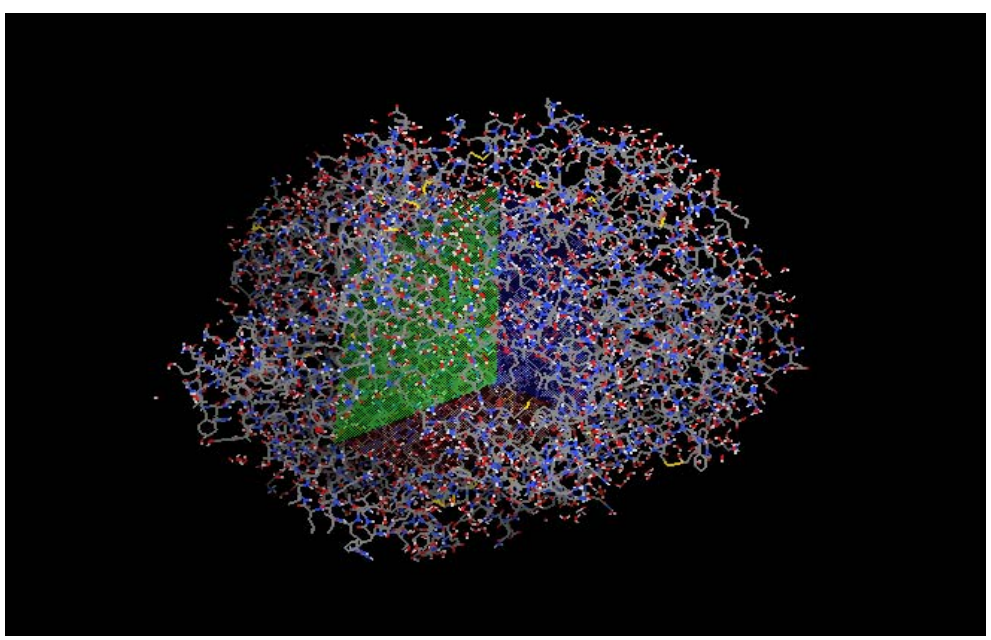

Figure 3: Grid box adjusted to the Ibuprofen-COX2 model

A validation docking of the crystal structure of murine (mu) COX-2 in complex with Ibuprofen (IBP) (Orlando and al. 2015). (PDB ID: 4PH9) (http: / /www.rcsb.org/pdb). Was performed on Autodock vina after visualization in discovery studio and processing of the ligand and receptor.

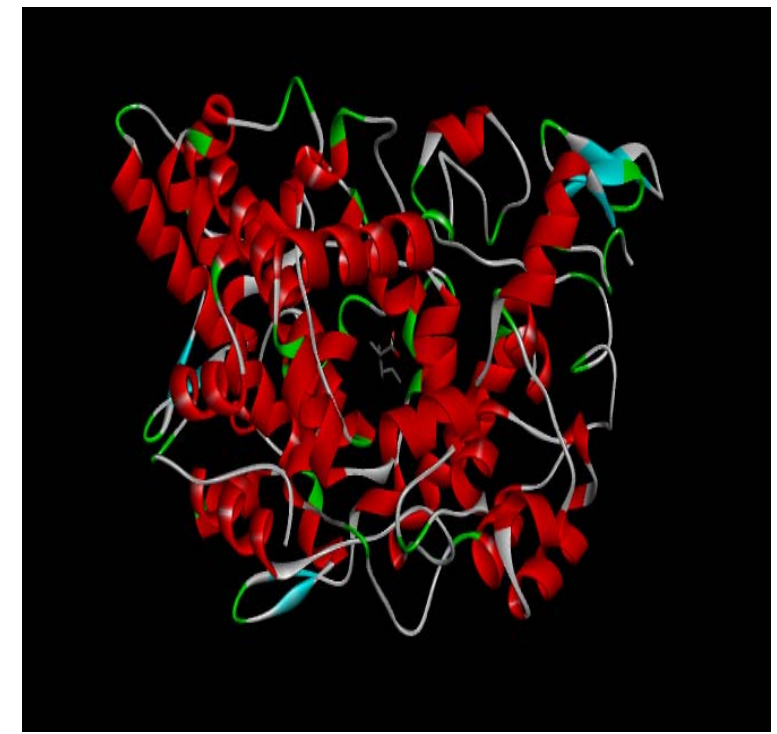

Figure 4a

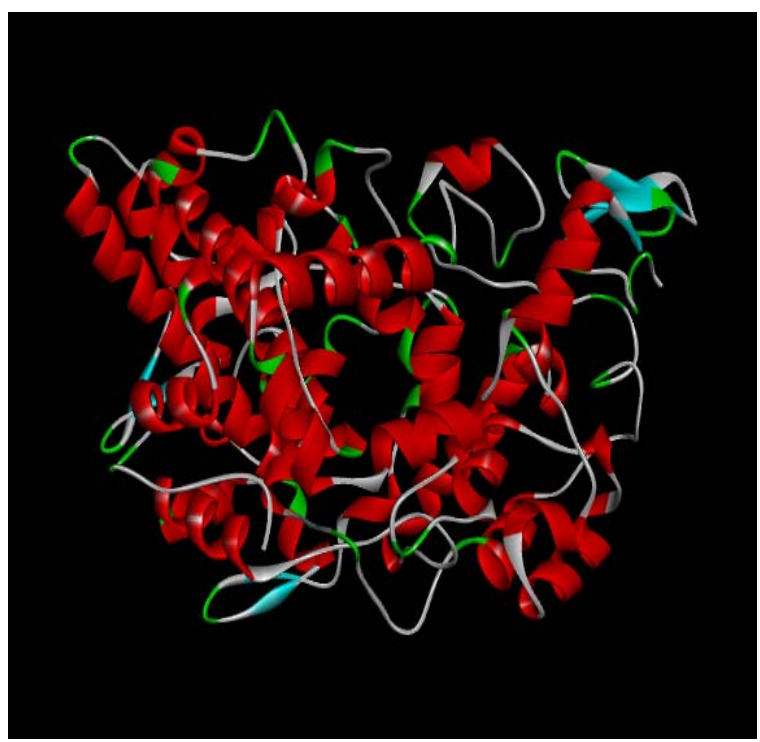

Figure 4b

Figure 4: COX2 pocket (4a: Binding Ibuprofen, 4b Free)

The complex formed by Ibuprofene-COX 2 from the experimental model of Orlando et al has a very low energy value and gives a docking score (Affinity: -7.3 ( $\mathrm{kcal} / \mathrm{mol}$ ) with a mean square deviation of $(\mathrm{RMSD}=23.884$ ).

The interactions between COX2-Ibuprofen have been illustrated in Figures $5 \mathrm{a}$ and $5 \mathrm{~b}$. 


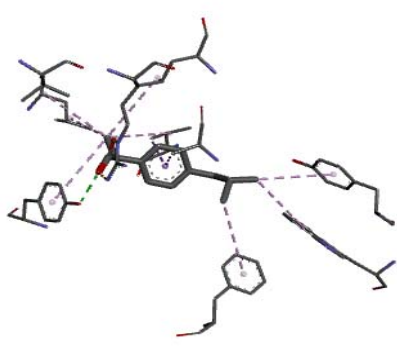

Figure 5a

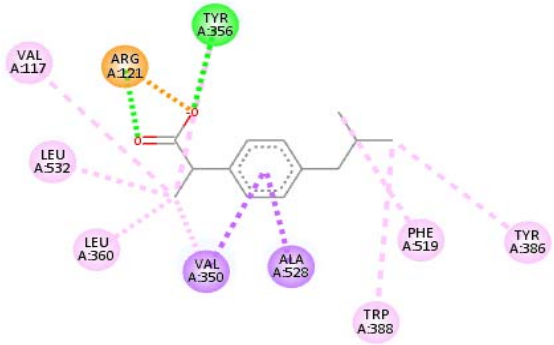

Figure $5 b$

Figures 5a and 5b: receptor-ligand interactions on a 2D diagram

\section{Discussion:}

Furse et al studied molecular dynamics simulations of COX-1 and COX-2 enzymes with its human substrate (arachidonic acid). These simulations were compared to reference simulations of arachidonate in solution to explore the effect of the enzyme on the conformation and positioning of the substrate in the active site. The simulations suggest that the substrate has greater conformational freedom in the COX-2 active site compared to COX-1, which is consistent with the greater volume of COX-2 active site observed in crystal structures on $\mathrm{X}-$ rays (Furse and al. 2006).

Cyclooxygenases are functional homodimers. In our work, the active site was identified in the A chain of cox2 in the cox 2 structure linked to ibuprofen. Our simulations only involved a single monomer, like some work (Cukier and al. 2002), or others that focused on an even smaller fragment of the protein, like the membrane binding domain (Nina and al. 2000) or the membrane and helix binding domain comprising the active site of cyclooxygenase (García-Nieto and al. 2000).

In addition, previous studies have indicated that many different NSAIDs (including IBP) bind tightly to a single monomer of the COX-2 dimer and allosterically inhibit oxygenation of the substrate into the partner monomer (Dong and al. 2011), (Duggan and al. 2011).

The results of our docking confirm those found by Orlando et al on the experimental level. Orlando et al identified ibuprofen in an area of the enzyme between the opening of the substrate channel and the top of the active site (Orlando and al. 2015)

Looking at gastrointestinal outcomes as the primary endpoint, preliminary evidence has shown the link between COX inhibition and the risk of cardiovascular disease. The VioXX trial in patients with rheumatoid arthritis treated with Rofecoxib were five times more likely to have a myocardial infarction than patients on nonselective anti-inflammatory inhibitor Naproxen (Bombardier and al. 2000) .

Following the results of the Adenomatous Polyp PRevention On Vioxx (APPROVe) study, rofecoxib was withdrawn from the market in 2004(Baron and al. 2008)

A meta-analysis of 280 trials of nonsteroidal anti-inflammatory drugs versus placebo showed that high dose naproxen was associated with a risk, albeit a low one, of vascular events (Bhala and al. 2013). Furthermore, the risk of cardiovascular disease was not equal for all COX-2 inhibitors. Questions also remained about the dose and duration of use of nonsteroidal anti-inflammatory drugs associated with a high risk of cardiovascular disease.

\section{Conclusion}

Our docking validated the experimental results known in current practice concerning the inhibition of cyclo oxygenase by ibuprofen. Molecular docking becomes an essential step in drug discovery so that new exoges ligands can be identified 


\section{References}

[1] Baron, J. A., R. S. Sandler, R. S. Bresalier, A. Lanas, D. G. Morton, R. Riddell, E. R. Iverson and D. L. Demets (2008). "Cardiovascular events associated with rofecoxib: final analysis of the APPROVe trial." Lancet 372(9651): 1756-1764.

[2] Bhala, N., J. Emberson, A. Merhi, S. Abramson, N. Arber, J. A. Baron, C. Bombardier, C. Cannon, M. E. Farkouh, G. A. FitzGerald, P. Goss, H. Halls, E. Hawk, C. Hawkey, C. Hennekens, M. Hochberg, L. E. Holland, P. M. Kearney, L. Laine, A. Lanas, P. Lance, A. Laupacis, J. Oates, C. Patrono, T. J. Schnitzer, S. Solomon, P. Tugwell, K. Wilson, J. Wittes and C. Baigent (2013). "Vascular and upper gastrointestinal effects of non-steroidal anti-inflammatory drugs: meta-analyses of individual participant data from randomised trials." Lancet 382(9894): 769-779.

[3] Bombardier, C., L. Laine, A. Reicin, D. Shapiro, R. Burgos-Vargas, B. Davis, R. Day, M. B. Ferraz, C. J. Hawkey, M. C. Hochberg, T. K. Kvien and T. J. Schnitzer (2000). "Comparison of upper gastrointestinal toxicity of rofecoxib and naproxen in patients with rheumatoid arthritis. VIGOR Study Group." N Engl J Med 343(21): 1520-1528, 1522 p following 1528.

[4] Cukier, R. I. and S. Seibold (2002). "Molecular dynamics simulations of prostaglandin endoperoxide H synthase-1. Role of water and the mechanism of compound I formation from hydrogen peroxide." The Journal of Physical Chemistry B 106(46): 12031-12044.

[5] Day, M. (2020). "Covid-19: ibuprofen should not be used for managing symptoms, say doctors and scientists." Bmj 368: $\mathrm{m} 1086$.

[6] Dong, L., N. P. Sharma, B. J. Jurban and W. L. Smith (2013). "Pre-existent asymmetry in the human cyclooxygenase-2 sequence homodimer." Journal of Biological Chemistry 288(40): 28641-28655.

[7] Dong, L., A. J. Vecchio, N. P. Sharma, B. J. Jurban, M. G. Malkowski and W. L. Smith (2011). "Human cyclooxygenase-2 is a sequence homodimer that functions as a conformational heterodimer." J Biol Chem 286(21): 19035-19046.

[8] Duggan, K. C., D. J. Hermanson, J. Musee, J. J. Prusakiewicz, J. L. Scheib, B. D. Carter, S. Banerjee, J. A. Oates and L. J. Marnett (2011). "(R)-Profens are substrate-selective inhibitors of endocannabinoid oxygenation by COX-2." Nat Chem Biol 7(11): 803-809.

[9] Furse, K. E., D. A. Pratt, N. A. Porter and T. P. Lybrand (2006). "Molecular dynamics simulations of arachidonic acid complexes with COX-1 and COX-2: insights into equilibrium behavior." Biochemistry 45(10): 3189-3205.

[10] García-Nieto, R., C. Pérez and F. Gago (2000). "Automated docking and molecular dynamics simulations of nimesulide in the cyclooxygenase active site of human prostaglandin-endoperoxide synthase-2 (COX-2)." J Comput Aided Mol Des 14(2): 147-160.

[11] Gislason, G. H., S. Jacobsen, J. N. Rasmussen, S. Rasmussen, P. Buch, J. Friberg, T. K. Schramm, S. Z. Abildstrom, L. Køber, M. Madsen and C. Torp-Pedersen (2006). "Risk of death or reinfarction associated with the use of selective cyclooxygenase-2 inhibitors and nonselective nonsteroidal antiinflammatory drugs after acute myocardial infarction." Circulation 113(25): 2906-2913.

[12] Karsh, J. (2006). "Can anti-inflammatories be safe?" CMAJ : Canadian Medical Association Journal 175(5): $451-451$.

[13] Kurumbail, R. G., A. M. Stevens, J. K. Gierse, J. J. McDonald, R. A. Stegeman, J. Y. Pak, D. Gildehaus, T. D. Penning, K. Seibert and P. C. Isakson (1996). "Structural basis for selective inhibition of cyclooxygenase-2 by anti-inflammatory agents." Nature 384(6610): 644-648.

[14] Laneuville, O., D. K. Breuer, D. L. Dewitt, T. Hla, C. D. Funk and W. L. Smith (1994). "Differential inhibition of human prostaglandin endoperoxide H synthases-1 and -2 by nonsteroidal anti-inflammatory drugs." J Pharmacol Exp Ther 271(2): 927-934.

[15] Liu, G., S. Chen, J. Zhong, K. Teng and Y. Yin (2017). "Crosstalk between Tryptophan Metabolism and Cardiovascular Disease, Mechanisms, and Therapeutic Implications." Oxid Med Cell Longev 2017: 1602074.

[16] Mitchener, M. M., D. J. Hermanson, E. M. Shockley, H. A. Brown, C. W. Lindsley, J. Reese, C. A. Rouzer, C. F. Lopez and L. J. Marnett (2015). "Competition and allostery govern substrate selectivity of cyclooxygenase-2." Proceedings of the National Academy of Sciences 112(40): 12366-12371.

[17] Nina, M., S. Bernèche and B. Roux (2000). "Anchoring of a monotopic membrane protein: the binding of prostaglandin H2 synthase-1 to the surface of a phospholipid bilayer." Eur Biophys J 29(6): 439-454.

[18] Orlando, B. J., M. J. Lucido and M. G. Malkowski (2015). "The structure of ibuprofen bound to cyclooxygenase-2." Journal of structural biology 189(1): 62-66.

[19] Picot, D., P. J. Loll and R. M. Garavito (1994). "The X-ray crystal structure of the membrane protein prostaglandin H2 synthase-1." Nature 367(6460): 243-249.

[20] Selinsky, B. S., K. Gupta, C. T. Sharkey and P. J. Loll (2001). "Structural analysis of NSAID binding by prostaglandin H2 synthase: time-dependent and time-independent inhibitors elicit identical enzyme conformations." Biochemistry 40(17): 5172-5180.

[21] Smith, W. L., Y. Urade and P. J. Jakobsson (2011). "Enzymes of the cyclooxygenase pathways of prostanoid biosynthesis." Chem Rev 111(10): 5821-5865.

[22] Vecchio, A. J. and M. G. Malkowski (2011). "The structure of NS-398 bound to cyclooxygenase-2." J Struct Biol 176(2): $254-258$.

[23] Voiriot, G., Q. Philippot, A. Elabbadi, C. Elbim, M. Chalumeau and M. Fartoukh (2019). "Risks Related to the Use of Non-Steroidal Anti-Inflammatory Drugs in Community-Acquired Pneumonia in Adult and Pediatric Patients." J Clin Med 8(6). 